\title{
Using GPS tracking for fruit bat conservation
}

\author{
Isabella Mande, Amelaid Houmadi, Ishaka Said, Badrane Ben Ali Abdou \\ A bdoul-Kader Fardane, Kilian Egger-Peitler, Ryszard Oleksy \\ Hugh Doulton and Sourette Said Ali Chainane
}

\begin{abstract}
Understanding the ecology of species is key to the development of effective conservation measures. For many fruit bat species, however, even baseline knowledge of ecology and behaviour is lacking. To identify feeding sites of the Critically Endangered Livingstone's flying fox Pteropus livingstonii on the island of Anjouan, Comoros, we piloted the use of GPS loggers. Two bats (one female, one male) were tagged in early 2019, and data collected for 217 and 35 days, respectively. Acceleration data facilitated the classification of location points into behavioural categories. Potential feeding sites were located by cluster analysis of all location points that were attributed to a behavioural category in which feeding could occur. One important feeding site was located in an agricultural area. This is the first time quantitative behavioural data have been collected for Livingstone's flying foxes, providing insight into the ecological needs of this threatened species. These findings have the potential to inform applied conservation management decisions for protecting the resources required for the survival of this species.
\end{abstract}

Keywords Anjouan, applied conservation, Comoros, GPS loggers, Livingstone's fruit bat, Pteropus livingstonii

W ith a total population of c. 1,200 individuals endemic to two islands of the Comoros archipelago, Western Indian Ocean, Livingstone's flying fox Pteropus livingstonii is categorized as Critically Endangered on the IUCN Red List (Sewall et al., 2016). This fruit bat is primarily threatened by habitat loss (Trewhella et al., 2001; Granek, 2002; Daniel et al., 2017), as timber extraction and unsustainable agricultural practices have led to an $80 \%$ decrease in forest cover since 1995 (Boussougou et al., 2015; Doulton et al., 2015). The local NGO Dahari currently works to protect the species' 15 known roost sites on Anjouan (Dahari, 2018). We piloted the use of GPS loggers on this bat species

IsABELla MANDL (Corresponding author, (D) orcid.org/0000-0002-7190-9778), Amelaid Houmadi, Ishaka Said, Badrane Ben Ali Abdou, Abdoul-Kader FARdane and Hugh Doulton Dahari, Mutsamudu-Anjouan, Comoros E-mail isabella.mandl@daharicomores.org

Sourette Said Ali Chainane Université des Comores, Patsy-Anjouan, Comoros

KILIAN EgGer-Peitler ( D orcid.org/0000-0002-7442-8822) Queen's University, Kingston, Ontario, Canada

RYsZARD Oleksy Ecosystem Restoration Alliance, Mauritius

Received 16 December 2019. Revision requested 18 February 2020.

Accepted 15 June 2020. First published online 31 March 2021. to evaluate the applicability of this method for identifying feeding sites and thus improving conservation measures.

Two Livingstone's flying foxes were captured in early 2019 (Fig. 1, Table 1), during 19.00-21.00 using custom-made canopy nets (length $\times$ height $=7 \times 3 \mathrm{~m}$, mesh size: $10 \times 10 \mathrm{~cm}$ ) mounted $7 \mathrm{~m}$ above the ground. The nets were monitored continuously, and captured bats were removed immediately. For each bat we recorded standard measurements (forearm, wing and body length, weight, and reproductive status according to Racey, 2009; Table 1). We fitted GPS loggers (15 g Bird Solar, e-obs, Grünwald, Germany) mounted on collars (handmade, including a weak link allowing the collar to fall off after a maximum of 10 months). Together the GPS logger and collar weighed $20 \mathrm{~g}$, not exceeding the recommended $5 \%$ of animal body weight (Aldridge \& Brigham, 1988). The loggers were set to record one location every 90 seconds when moving and one location every 6 hours when stationary. Internal accelerometers recorded movement across three axes in bursts of 4 seconds per minute. Data were retrieved at roost sites by remote download via UHF.

Home ranges were computed as $95 \%$ kernel density estimates in $R 3.6$ ( $\mathrm{R}$ Core Team, 2019), using the package $\mathrm{ctmm}$ (Calabrese et al., 2016). Accelerometer data facilitated an approximate classification of behavioural categories based on the orientations and oscillations of the three axes in the Movebank Acceleration Viewer (Wikelski \& Kays, 2019): resting (the animal is stationary, head downwards), flying (the animal is moving across the landscape, head parallel to ground), scratching (the animal is stationary, head downwards, using its leg to scratch its fur) and moving/ climbing (the animal is changing position within a tree, head position is variable; Fig. 2). These categories were based on Weber et al. (2015) and O'Mara et al. (2019), and preliminary behavioural observation of the study individuals: we observed the two collared individuals for $15 \mathrm{~min}$ utes after release, noting behaviours continuously until the bats were out of sight. These behaviours were matched with the acceleration data for the time of observation. The remaining acceleration data, and all corresponding location points, were subsequently classed into the behavioural categories. The data were additionally validated by visualization of location using QGIS 2.18 (QGIS Development Team, 2019); for example, flying behaviours only occur along a flight path.

The GPS loggers recorded data for 217 and 35 days for the female and the male, respectively. Both individuals covered 


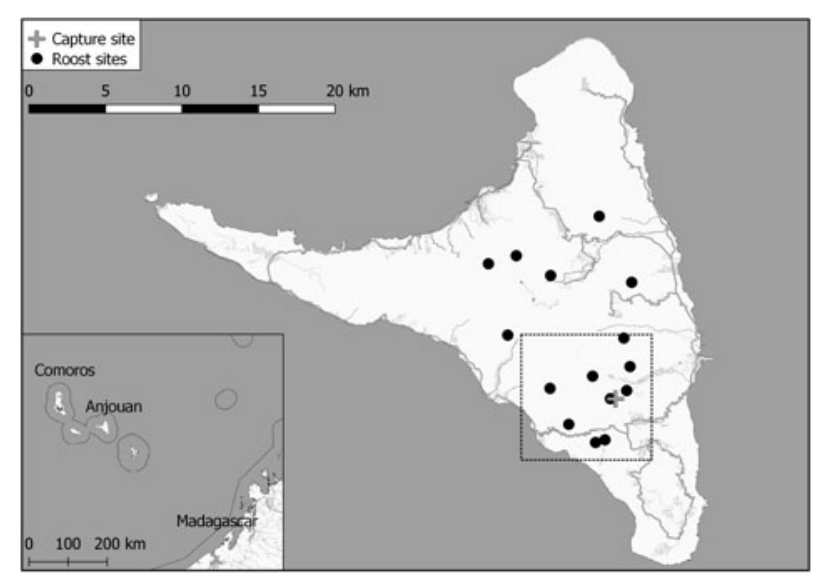

Fig. 1 Anjouan island in the Comoros archipelago, Western Indian Ocean, showing the 15 known long-term roost sites of Pteropus livingstonii and the site where the two individuals were captured. The dashed rectangle indicates the area covered by Fig. 3 .

a mean area of $13.1 \pm \mathrm{SD} 1.7 \mathrm{~km}^{2}$ and frequented 5-8 known roost sites within the observation period (Fig. 3a). For details of path lengths and home range sizes, see Table 1.

In the complete dataset 4,086 (female) and 1,557 (male) location points were attributed to moving/climbing. As only baseline behaviours could be determined, moving/ climbing behaviour probably included translocation within the same tree as well as feeding. All points categorized as moving/climbing were therefore treated as potential feeding sites. We conducted a cluster analysis of these points, grouping them based on distance, with the $R$ package geosphere (Hijmans, 2019). We computed 100\% minimum convex polygons for each of the clusters using the $R$ package adehabitatHR (Calenge, 2006), illustrating potential feeding

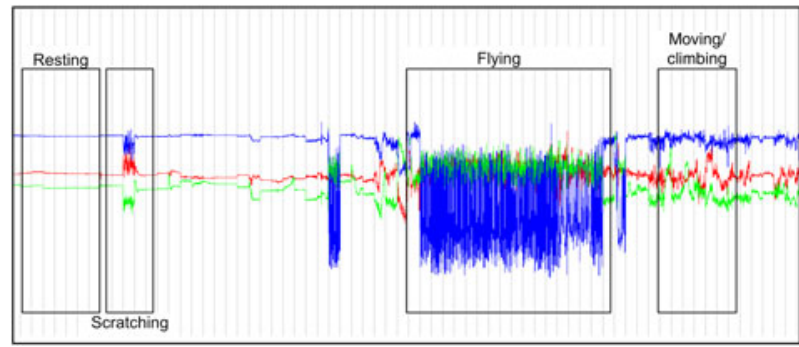

FIG. 2 Screenshot of the Movebank Acceleration Viewer (Wikelski \& Kays, 2019), showing, from top to bottom, the oscillations along the $\mathrm{z}, \mathrm{x}$ and $\mathrm{y}$ axes recorded by the GPS loggers. The acceleration data were used to distinguish between behavioural categories (resting, scratching, flying and moving/ climbing).

areas (Fig. 3b, Table 1). Overlap of potential feeding areas between the two individuals was $2.7 \mathrm{~km}^{2}$. We subsequently ground-truthed the area with the greatest overlap (Fig. $3 \mathrm{~b}$ ), and, by conducting opportunistic behavioural observations of Livingstone's flying foxes present in the trees during 17.00-21.00, confirmed that many trees were feeding trees. The feeding trees were located in agricultural fields interspersed with individual native and non-native trees. There was no natural forest in the area.

These findings demonstrate that GPS technology facilitates the detection of feeding sites and the identification of landscape use by Livingstone's flying foxes. Individuals displayed flexibility in roost selection, with both individuals visiting and resting in at least five known roost sites, similar to what has been observed for other flying foxes (Palmer \& Woinarski, 2000; Vardon et al., 2001; Banack \& Grant, 2016; Oleksy et al., 2019).

TABLE 1 Capture information and GPS data for two Pteropus livingstonii tagged with GPS loggers on Anjouan, Comoros.

\begin{tabular}{lll}
\hline & Female & Male \\
\hline Capture date & 26 Jan. 2019 & 5 Feb. 2019 \\
Measurements & & 730 \\
Weight $(\mathrm{g})$ & 530 & 18.5 \\
Forearm length $(\mathrm{cm})$ & 15.5 & 61 \\
Wing length $(\mathrm{cm})$ & 54 & 17.5 \\
Body length $(\mathrm{cm})$ & 15.0 & Reproductive/adult \\
Reproductive status/age & Nulliparous/adult & \\
Results & & 35 \\
Number of days tracked & 217 & 4,840 \\
Number of GPS fixes & 9,759 & 5 \\
Number of roosts visited & 8 & $1.6 \pm 0.7$ \\
Mean \pm SD number days of consecutive days spent at individual roosts & $1.8 \pm 0.6$ & 457.4 \\
Total distance travelled $\left(\mathrm{km}^{2}\right.$ & $190.4^{1}$ & $12.7 \pm 5.7$ \\
Mean \pm SD daily distance $(\mathrm{km})$ & $9.5 \pm 4.5^{1}$ & 11.4 \\
$95 \%$ kernel isopleth $\left(\mathrm{km}^{2}\right)$ & 14.8 & 3.4 \\
Potential feeding areas $\left(\mathrm{km}^{2}, 100 \%\right.$ minimum convex polygons) & 5.9 & \\
\hline
\end{tabular}

${ }^{1}$ Based on data for 26 Jan.-14 Feb. 2019; the remaining dates were excluded from path length analysis as the tag lost battery power and subsequently did not record GPS points consistently. 


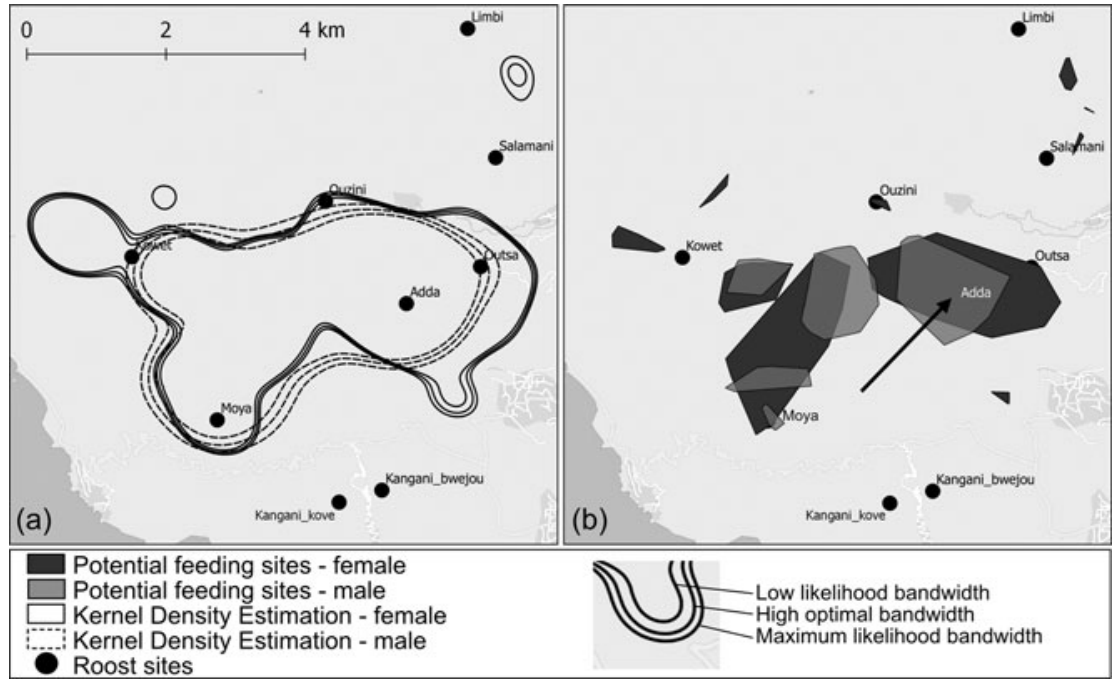

FIG. 3 Movement data of two individual P. livingstonii on Anjouan (Fig. 1) were used to estimate $95 \%$ kernel density ranges, presented as low likelihood, high optimal, and maximum likelihood bandwidth home range areas (a), and polygons depicting potential feeding areas (b). Roost sites are named according to the nearest villages. The arrow indicates the area where flying fox feeding behaviour was ground-truthed.
Natural, undisturbed forest occurs only in fragments across Anjouan, and only three long-term roosts are located in forest habitat (Daniel et al., 2017). That feeding sites were in farmed areas was unexpected, based on predictive modelling (Ibouroi et al., 2018). However, Ibouroi et al. (2018) found that flying fox presence was correlated with tall trees, which may explain their persistence in a landscape dominated by agroforestry that harbours old-growth, native trees (Trewhella et al., 2001).

Our data and analyses of the movement of Livingstone's flying fox have potential to help improve conservation of the species by identifying areas of roosting and feeding, and to support targeted reforestation. We plan to continue research on this Critically Endangered species, using GPS tracking as a way of identifying landscape use and feeding trees, to increase the protection of this threatened bat species and its habitat.

Acknowledgements We thank Ernest Seamark for providing training and equipment, Marc Büntjen for help with GPS tag programming, and Pascal Fust for scientific input in the planning phase. This study was funded by The Rufford Foundation and the Critical Ecosystems Partnership Fund.

Author contributions Study design: IM, AH, RO; collar design: KE-P, RO; fieldwork: IM, AH, KE-P, IS, BBAA, A-KF; data analysis: IM; writing: IM, HD, SSAC; project oversight: SSAC.

\section{Conflicts of interest None.}

Ethical standards This research complied with the Oryx guidelines on ethical standards and with those of Sherwin et al. (2003). Animal handling was kept to a minimum and only the required number of individuals were captured. All researchers handling bats wore protective gloves and equipment was disinfected after each use to avoid the spread of disease. The research was conducted by Dahari and the University of Comoros with permission of the Comorian government under permits No. 94-018/AF (22 June 1994) and No. 01/31/MPE/CAB.

\section{References}

Aldridge, H.D.J.N. \& Brigham, R.M. (1988) Load carrying and maneuverability in an insectivorous bat a test of the $5 \%$ 'rule' of radio-telemetry. Journal of Mammalogy, 69, 379-382.

BANACK, S.A. \& GRANT, G.S. (2016) Spatial and temporal movement patterns of the flying fox, Pteropus tnganus, in American Samoa. The Journal of Wildlife Management, 66, 1154-1163.

Boussougou, G.B., Brou, Y.T. \& Mohamed, I. (2015) Changements de la couverture forestière dans l'île d'Anjouan entre 1995 et 2014. In Proceedings of the Spatial Analysis and GEOmatics Conference (eds H. Baazaoui, C. Claramunt \& M. Haddad), pp. 1-14. SAGEO, Hammamet, Tunisia.

Calabrese, J.M., Fleming, C.H. \& Gurarie, E. (2016) Ctmm: An $R$ package for analyzing animal relocation data as a continuous-time stochastic process. Methods in Ecology and Evolution, 7, 1124-1132.

Calenge, C. (2006) The package adehabitat for the $R$ software: a tool for the analysis of space and habitat use by animals. Ecological Modelling, 197, 516-519.

Dahari (2018) Rapport Annuel. Mutsamudu, Anjouan, Comoros. daharicomores.org/wp-content/uploads/2020/12/Rapport_annuel_ 2018.pdf [accessed 24 February 2021].

Daniel, B.M., Green, K.E., Doulton, H., Salim, D.M., Said, I., Hudson, M. et al. (2017) A bat on the brink? A range-wide survey of the Critically Endangered Livingstone's fruit bat Pteropus livingstonii. Oryx, 51, 742-751.

Doulton, H., Mohamed, M., Shepherd, G., Mohamed, S., Ali, B. \& Maddison, N. (2015) Competing land-use in a small island developing state: using landscape approaches to manage sustainable outcomes in the Comoro Islands. In XIV World Forestry Congress (eds A. Sarre \& S. Lapstun), pp. 1-9. Food and Agriculture Organization of the United Nations, Durban, South Africa.

Granek, E. (2002) Conservation of Pteropus livingstonii based on roost site habitat characteristics on Anjouan and Moheli, Comoros islands. Biological Conservation, 108, 93-100.

Hijmans, R.J. (2019) Geosphere: Spherical Trigonometry. R package version 1.5-10. CRAN.R-project.org/package=geosphere [accessed 22 July 2020].

Ibouroi, M.T., Cheha, A. \& Astruc, G. (2018) A habitat suitability analysis at multi-spatial scale of two sympatric flying fox species 
reveals the urgent need for conservation action. Biodiversity and Conservation, 27, 2395-2423.

Oleksy, R.Z., Ayady, C.L., Tatayah, V., Jones, C., Howey, P.W., Froidevaux, J.S.P. et al. (2019) The movement ecology of the Mauritian flying fox (Pteropus niger): a long-term study using solar-powered GSM/GPS tags. Movement Ecology, 7, 1-12.

O’Mara, M.T., Scharf, A.K., Fahr, J., Abedi-Lartey, M., Wikelski, M., Dechmann, D.K.N. \& SAFi, K. (2019) Overall dynamic body acceleration in straw-colored fruit bats increases in headwinds but not with airspeed. Frontiers in Ecology and Evolution, 7, 200.

PALMER, C. \& Woinarski, J.C.Z. (2000) Seasonal roosts and foraging movements of the black flying fox (Pteropus alecto) in the Northern Territory: resource tracking in a landscape mosaic. Wildlife Research, 27, 169-178.

QGIS Development Team (2019) QGIS Geographic Information System. Open Source Geospatial Foundation Project. qgis.osgeo.org [accessed 2019].

RACEY, P.A. (2009) Reproductive assessment of bats. In Ecological and Behavioural Methods for the Study of Bats (eds T.H. Kunz \& S. Parsons), pp. 249-264. Johns Hopkins University Press, Baltimore, USA.

R Core TeAm (2019) R: A Language and Environment for Statistical Computing. R Foundation for Statistical Computing, Vienna, Austria. R-project.org [accessed 22 July 2020].
Sewall, B.J., Young, R., Trewhella, W.J., Rodríguez-Clark, K.M. \& Granek, E.F. (2016) Pteropus livingstonii. In The IUCN Red List of Threatened Species 2016: e.T18732A22081502. dx.doi.org/10. 2305/IUCN.UK.2016-2.RLTS.T18732A22081502.en [accessed 1 October 2020].

Sherwin, C.M., Christiansen, S.B., Duncan, I.J.H., Erhard, H.W., Lay, D.C., Mench, J.A. et al. (2003) Guidelines for the ethical use of animals in applied animal behaviour research. Applied Animal Behaviour Science, 81, 291-305.

Trewhella, W.J., Rodriguez-Clark, K.M., Davies, J.G., Reason, P.F. \& WRAY, S. (2001) Sympatric fruit bat species (Chiroptera: Pteropodidae) in the Comoro Isalnds (Western Indian Ocean): diurnality, feeding interactions and their conservation implications. Acta Chiropterologica, 3, 135-147.

VArdon, M.J., Brocklehurst, P.S., Woinarski, J.C.Z., Cunningham, R.B., Donnelly, C.F. \& Tidemann, C.R. (2001) Seasonal habitat use by flying-foxes, Pteropus alecto and $P$. scapulatus (Megachiroptera), in monsoonal Australia. Journal of Zoological Society London, 253, 523-535.

Weber, N., Duengkae, P., Fahr, J., Dechmann, D.K., Phensakul, P., Kнuмвисна, W. et al. (2015) High-resolution GPS tracking of Lyle's flying fox between temples and orchards in central Thailand. The Journal of Wildlife Management, 79, 957-968.

WiKelski, M. \& Kays, R. (2019) Movebank: Archive, Analysis and Sharing of Animal Movement Data. Max Planck Institute for Animal Behavior, Radolfzell, Germany. movebank.org [accessed June 2019]. 